\title{
Interaction between air bubbles and superhydrophobic surfaces in aqueous solutions
}

\author{
Chen Shi ${ }^{1}$, Xin Cui ${ }^{1}$, Xurui Zhang ${ }^{1}$, Plamen Tchoukov ${ }^{1}$, Qingxia Liu ${ }^{1}$, Noemi Encinas ${ }^{2}$, Maxime \\ Paven $^{2}$, Florian Geyer ${ }^{2}$, Doris Vollmer ${ }^{2}$, Zhenghe $\mathrm{Xu}^{1}$, Hans-Jürgen Butt ${ }^{2 *}$ and Hongbo Zeng ${ }^{1}$ \\ ${ }^{1}$ Department of Chemical and Materials Engineering, University of Alberta, Canada \\ ${ }^{2}$ Max Planck Institute for Polymer Research, Ackermannweg 10, 55128 Mainz, Germany \\ *Correspondence to butt@mpip-mainz.mpg.de
}

\begin{abstract}
Superhydrophobic surfaces are usually characterized by a high apparent contact angle of water drops in air. Here we analyze the inverse situation: Rather than focusing on water repellency in air we measure the attractive interaction of air bubbles and superhydrophobic surfaces in water. Forces were measured between microbubbles with radii $R$ of $40-90 \mu \mathrm{m}$ attached to an atomic force microscope cantilever and submerged superhydrophobic surfaces. In addition, forces between macroscopic bubbles $(R=1.2 \mathrm{~mm})$ at the end of capillaries and superhydrophobic surfaces were measured. As superhydrophobic surfaces we applied soot-templated surfaces, nanofilament surfaces, micropillar arrays with flat top faces and decorated micropillars. Depending on the specific structure of the superhydrophobic surfaces and the presence and amount of entrapped air different interactions were observed. Soot-templated surfaces in the Cassie state showed superaerophilic behavior: Once the electrostatic double-layer force and a hydrodynamic repulsion were overcome, bubbles jumped onto the surface and fully merged with the entrapped air. On nanofilaments and micropillar arrays we observed in addition the formation of sessile bubbles with finite contact angles below $90^{\circ}$ or the attachment of bubbles, which retained their spherical shape.
\end{abstract}




\section{Introduction}

Wetting of a surface by a liquid is determined by the chemical composition and the three-dimensional topography on the nano- and micrometer scale. One example for a surface with special wetting properties are superhydrophobic surfaces, which strongly repel water. This repellency is typically quantified by a high apparent contact angle $\left(\Theta^{a p p}>150^{\circ}\right)$ and a low roll-off angle for droplets $\left(\alpha<5-10^{\circ}\right)$. High contact angles can be reached if the surface topography stabilizes a layer of air underneath the water, even if the roll-off angle exceeds $10^{\circ}$. This state is called the Cassie-state. ${ }^{1}$ When no air is entrapped and the whole surface of the solid substrate is in direct contact with water the surface is said to be in the Wenzel state. ${ }^{2}$ Superhydrophobic surfaces only show water repellent properties when they are in the Cassie state. Maintaining the Cassie state is therefore essential.

For many applications, e.g. for drag reduction ${ }^{3,4,5,6,7,8}$ in capillaries or for gas exchange membranes, ${ }^{9}$ superhydrophobic surfaces are submerged. On superhydrophobic surfaces in the Cassie state drag is reduced because the hydrodynamic boundary condition changes. A large part of solid-liquid interface with its no-slip boundary condition is replaced by water-air interface; a pure water-air interface cannot support shear. The effect is similar to the Leidenfrost effect of submerged hot surfaces ${ }^{10}$ but should be distinguished from the use of dispersed air bubbles to reduce hydrodynamic drag macroscopically (e.g. ${ }^{11}$ ). In the latter case dispersed bubbles reduce hydrodynamic drag of the liquid by bubble splitting, bubble deformability and providing compressibility to the liquid. In the first case drag reduction is caused by an effective slip.

In submerged samples, the air in the superhydrophobic surface is no longer connected to the atmosphere, as is the case for sessile drops. Then the lifetime of the Cassie state can be limited by the hydrostatic pressure and dissolution of gas in water. ${ }^{12,13,14,15}$ As the partial pressure of entrapped gas increases along with the hydrostatic pressure, gas is dissolved in water according to Henry's law. The resulting decrease in gas pressure destabilizes the Cassie state. Changes in the degree of saturation of water with gas could lead to a depletion of gas from the entrapped air, which further destabilizes the Cassie state. Such a change can for example be caused by a temporary decrease of temperature. Therefore, for longevity air needs to be replenished. ${ }^{16,17,18,19}$ Replenishing air has the additional advantage that temporary decreases of the thickness of the air layer for example caused by turbulent flow may be repaired. 
Bubbles dispersed in a liquid flowing over a submerged superhydrophobic surface may be used for replenishing air and to maintain the Cassie state. A prerequisite is, however, that bubbles merge with the entrapped air layer. The key for these processes is a favorable interaction of the bubble with a superhydrophobic surface. This interaction has been studied by imaging rising bubbles when they get into contact with superhydrophobic surfaces. $^{20,21}$ Depending on the specific wetting properties of the sample, bursting or pinning has been observed. Furthermore, Wang et al. measured a strong adhesive force when removing macroscopic air bubbles from natural and biomimetic rose petals. ${ }^{22}$

Here we describe direct force measurements for the interaction between bubbles with submerged superhydrophobic surfaces in the Cassie state. Force measurement between air bubbles and solid surfaces have been conducted using different techniques such as the AFM (atomic force microscope) colloidal probe technique $23,24,25,26$ and the surface forces apparatus (SFA). ${ }^{27}$ These techniques generally require smooth and transparent solid surfaces or particles. Recently, an AFM based technique for direct force measurements between bubbles ${ }^{28,29,} 30$ and between bubbles and solid surfaces ${ }^{31,32,33,34}$ has been developed. In this technique, a bubble is anchored on a hydrophobic region on a tipless AFM cantilever. Almost any type of solid/liquid surface and bubble can be tested without the limitation of surface requirement in solid colloidal probe method or SFA measurement. Although AFM itself cannot directly measure the absolute separation between deformable bubbles and surfaces, a theoretical model based on Reynolds lubrication theory and an augmented Young-Laplace equation has been applied to successfully interpret the measured force curves. ${ }^{34}$ By coupling the AFM bubble probe technique and reflection interference contrast microscopy (RICM), the interaction force and the spatiotemporal evolution of the thin water film between a bubble in water and mica surfaces was directly measured. ${ }^{34}$ Despite this progress, to our knowledge no report is available about direct force measurements between bubbles and submerged superhydrophobic surfaces.

\section{Materials and Methods}

All experiments were carried out at room temperature. The following chemicals were used: Tetraethylorthosilicate (TEOS, 98\%, Sigma-Aldrich, Germany), $1 \mathrm{H}, 1 \mathrm{H}, 2 \mathrm{H}, 2 \mathrm{H}$-perfluorooctyltrichlorosilane (PFOTS, 97\%, Sigma-Aldrich, Germany), trichloromethylsilane (TCMS, 99\%, Sigma-Aldrich, Germany), 1H,1H,2H,2H-perfluorodecyltrichlorosilane (PFDTS, 98\%, Alfa Aesar, Germany), hexane (99,99\%, Fisher Chemical, Germany), aqueous ammonia solution 
(28 wt.\%, VWR International and Normapur, Germany), and photoresist SU-8 (Microchem, Germany). Reagents were used as received. Paraffin candles were obtained from the local supermarket. Polished silicon wafers were obtained from Si-Mat (Germany). Glass slides of $24 \times 60 \mathrm{~mm}^{2}$ and $170 \pm 5 \mu \mathrm{m}$ thickness were obtained from Carl Roth (Germany).

\section{Superhydrophobic surfaces}

Four types of superhydrophobic surfaces were prepared and analyzed: (1) Soot-templated superamphiphobic surfaces, (2) superamphiphobic surfaces consisting of nanofilaments, (3) arrays of cylindrical micropillars, and (4) arrays of micropillars decorated with microspheres at the top faces. Apparent receding contact angles and roll-off angles for water are given in table 1 . We report apparent receding contact angles because the receding rather than the advancing contact angle determines the mobility of sliding drops. ${ }^{35}$

\begin{tabular}{|c|c|c|}
\hline & $\Theta_{r}^{a p p}$ & $\begin{array}{c}\text { Roll-off } \\
\text { angle }\end{array}$ \\
\hline $\begin{array}{l}\text { Soot-templated } \\
600^{\circ} \mathrm{C}\end{array}$ & $>158^{\circ} \pm 4^{\circ}$ & $<1^{\circ}$ \\
\hline $\begin{array}{l}\text { Soot-templated } \\
1150^{\circ} \mathrm{C}\end{array}$ & $155^{\circ} \pm 5^{\circ}$ & $5-8^{\circ}$ \\
\hline Nanofilaments & $158^{\circ} \pm 4^{\circ}$ & $<1^{\circ}$ \\
\hline Micropillars & $140^{\circ} \pm 4^{\circ}$ & $15^{\circ}$ \\
\hline $\begin{array}{l}\text { Decorated } \\
\text { micropillars }\end{array}$ & $142^{\circ} \pm 2^{\circ}$ & $7^{\circ}$ \\
\hline
\end{tabular}

Table 1. Apparent receding contact angle $\left(\Theta_{r}{ }^{a p p}\right)$ measured in the sessile drop configuration and roll-off angle for a water drop of $5 \mu \mathrm{L}$ for the differently prepared superhydrophobic surfaces.

(1) Soot-templated surfaces (Fig. 1A,B) were prepared as described in ref. ${ }^{36}$. Silicon wafers of $1.5 \times 1.5 \mathrm{~cm}^{2}$ size were cleaned by supersonication in toluene, acetone, and ethanol for 5 min each. The wafers were dried at $0.25 \mathrm{bar}$ and $40^{\circ} \mathrm{C}$ in an oven. To reduce delamination a prelayer of silica was deposited on the wafers by chemical vapor deposition (CVD). Therefore the cleaned wafers were activated by oxygen plasma (300 W, 2 min) and subsequently transferred to a desiccators. The desiccator contained two $20 \mathrm{~mL}$ vials, one carrying $3 \mathrm{~mL}$ TEOS and the other $3 \mathrm{~mL}$ ammonium hydroxide solution ( $28 \mathrm{wt}$.\%). After $24 \mathrm{~h}$ 
of CVD the wafers were exposed to candle soot for $30 \mathrm{~s}$. The collected candle soot served as template and was coated with a silica shell. Therefore, the samples were placed again in a desiccator containing 2 vials of $3 \mathrm{~mL}$ TEOS and $3 \mathrm{~mL}$ ammonium hydroxide solution (28 wt.\%) for $24 \mathrm{~h}$. After silica coating the candle soot template was combusted in air at $600^{\circ} \mathrm{C}$ (Fig. $1 \mathrm{~A}$ ), $900^{\circ} \mathrm{C}$ for $3.5 \mathrm{~h}$ or at $1150^{\circ} \mathrm{C}$ (Fig. 1B) for $4 \mathrm{~h}$ (Oven: VKM-22, Linn High Therm $\mathrm{GmbH}$, Germany). After combustion the samples were hydrophobized by placing them in a desiccator together with a $20 \mathrm{~mL}$ vial containing $100 \mu \mathrm{L}$ PFOTS. The desiccator was evacuated to 25 mbar and the reaction proceeded for $3 \mathrm{~h}$ at room temperature. Finally, unreacted fluorosilane was removed from the samples by placing the samples in a vacuum chamber (100 mbar at $80{ }^{\circ} \mathrm{C}$ for $3 \mathrm{~h}$ ). These surfaces even show superamphiphobic properties and repel oils and surfactant solutions. ${ }^{36}$

(2) Silicone Nanofilaments (Fig. 1C) were prepared modifying the method described by Zhang and Seeger. ${ }^{37} 120 \mu \mathrm{L}$ of TCMS was added to a reaction chamber containing $50 \mathrm{~mL}$ of water-saturated hexane. The solution was stirred for $60 \mathrm{~s}$. Afterwards glass slides were immersed in the solution and the reaction chamber was sealed. After 3 days the coated glass slides were rinsed with hexane and dried under a nitrogen stream. The coated glass slides were activated in an oxygen plasma (Femto, Diener Electronic, $25 \mathrm{~W}, 2 \mathrm{~min}$ ) at an oxygen flow rate of $7 \mathrm{sccm}$ (standard cubic centimeters per minute, $\mathrm{cm}^{3} / \mathrm{min}$ ). A volume of $25 \mu \mathrm{L}$ of PFDTS was mixed with $50 \mathrm{~mL}$ of hexane. The activated samples were immersed in the solution for $20 \mathrm{~min}$. Afterwards the fluorinated samples were rinsed with hexane and dried under a nitrogen stream. The silicon nanofilament layers were $4 \mu \mathrm{m}$ thick.

(3) Arrays of micropillars (Fig. 1D). Square arrays of round flat-top micropillars of $10 \mu \mathrm{m}$ height, a center-to-center distance of $10 \mu \mathrm{m}$ and a diameter of $5 \mu \mathrm{m}$ were fabricated on $170 \mu \mathrm{m}$ thick glass slides by photolithography of the negative photoresist SU-8 (Microchem) as described in ref. ${ }^{38}$. Pillars were coated with a silica shell of $\approx 70 \mathrm{~nm}$ by a Stöber reaction to improve the mechanical stability. Therefore, after activation of the samples under $\mathrm{O}_{2}$ plasma (30 s, $150 \mathrm{~W}$, flow rate of $7 \mathrm{sccm}$ ) they were immersed in a solution of tetraethoxysilane (TES, $1.8 \mathrm{~mL}$ ) and ammonium hydroxide ( $28 \%$ in water, $4.2 \mathrm{~mL})$ in ethanol $(50 \mathrm{~mL})$ for $2.3 \mathrm{~h}$. In a final step, the micropillars were rinsed with ethanol and dried in a $\mathrm{N}_{2}$ stream. The silicon oxide was hydrophobized in an atmosphere of PFOTS for $3 \mathrm{~h}$, analogous to the procedure described to hydrophobize the soot-templated surfaces. For the pillar arrays we estimated ${ }^{39}$ the impalement pressure to be $5 \mathrm{kPa}$. For the soot-templated surfaces and the nanofilaments we expect the impalement pressure to be higher due to the smaller spacing between asperities. 
(4) Decorated micropillars (Fig. 1E). Colloidal monolayers of polystyrene particles were deposited on the micropillar arrays by self-assembly at the air-water interface of a Langmuir trough $\left(242 \mathrm{~cm}^{2}\right)$ using Milli-Q water as a sub-phase. ${ }^{40}$ The particles were synthesized by soap-free emulsion polymerization of styrene yielding monodisperse spherical particles of $1.4 \mu \mathrm{m}$ diameter. The substrates were immersed into the sub-phase and a colloidal dispersion in ethanol was added dropwise to the water/air interface. After $15 \mathrm{~min}$, the monolayer was compressed at $10 \mathrm{~mm} / \mathrm{min}$ before lowering the water level. In order to stabilize the system, the particle-decorated pillars were covered again with $a \approx 20$ $\mathrm{nm}$ thick silica shell by CVD of TES catalyzed by ammonia. They were finally fluorinated following the procedure to hydrophobize the micropillar arrays.



Figure 1: Scanning electron microscope (SEM) images of soot-templated surfaces annealed at $600^{\circ} \mathrm{C}(\mathrm{A})$ and $1150^{\circ} \mathrm{C}(\mathrm{B})$, nanofilament surfaces (C), arrays of micropillars (D), and arrays of micropillars decorated with microspheres at the top faces $(E)$. Samples were sputter coated with 6-12 nm Pt to enhance image quality (BalTec MED 020 Modular High Vacuum Coating System, Argon at $2 \times 10^{-5}$ bar, $\left.60 \mathrm{~mA}\right)$. Images were taken with a LEO 1530 Gemini, Zeiss SEM at a gun voltage of 0.7-1.0 kV (Inlens detector) or obtained at $1.5 \mathrm{kV}$ (Everhart-Thornley detector). 


\section{AFM bubble probe setup}

An AFM bubble probe technique was applied to directly measure forces between air bubbles and superhydrophobic surfaces (Fig. 2A). The glass disk of the fluid cell was slightly hydrophobized by immersion in a toluene solution containing $10 \mathrm{mM}$ octadecyltrichlorosilane (OTS) for $10 \mathrm{~s}$ to gain a water contact angle of $30^{\circ}-50^{\circ}$. The superhydrophobic sample was placed into solution after bubble generation. A customized tipless rectangular silicon AFM cantilever $\left(400 \times 70 \times 2 \mu \mathrm{m}^{3}\right)$ with a circular patch of gold (diameter $65 \mu \mathrm{m}$, thickness $30 \mathrm{~nm}$ ) was used for anchoring the air bubble. The gold patch on the cantilever was hydrophobized by immersing the cantilever in $10 \mathrm{mM}$ 1-decanethiol in ethanol solution overnight to gain stronger hydrophobicity than the glass disk of the fluid cell, which facilitated easy bubble pick-up. A bubble probe was created by bringing down the hydrophobized tipless cantilever to contact with an air bubble (radius $40-90 \mu \mathrm{m}$ ) on the bottom glass. Then the cantilever was carefully elevated to detach the bubble from the glass disk. Afterwards, the bubble probe was moved above the substrate surface and force measurements were conducted by driving the bubble close to and away from the surface by a piezo actuator at defined nominal velocity. The $Z$ piezo displacement, cantilever deflection and force were recorded by the AFM software. Calibration of the cantilever's spring constant was conducted using the method of Hutter and Bechhoefer before bubble loading. ${ }^{41}$ The volume of the measuring cell was $3-5 \mathrm{~mL}$ and the submerging depth of the air bubble (attached to the cantilever) was $0.5-1 \mathrm{~mm}$. More details about the set up are described in refs. ${ }^{33,34}$.
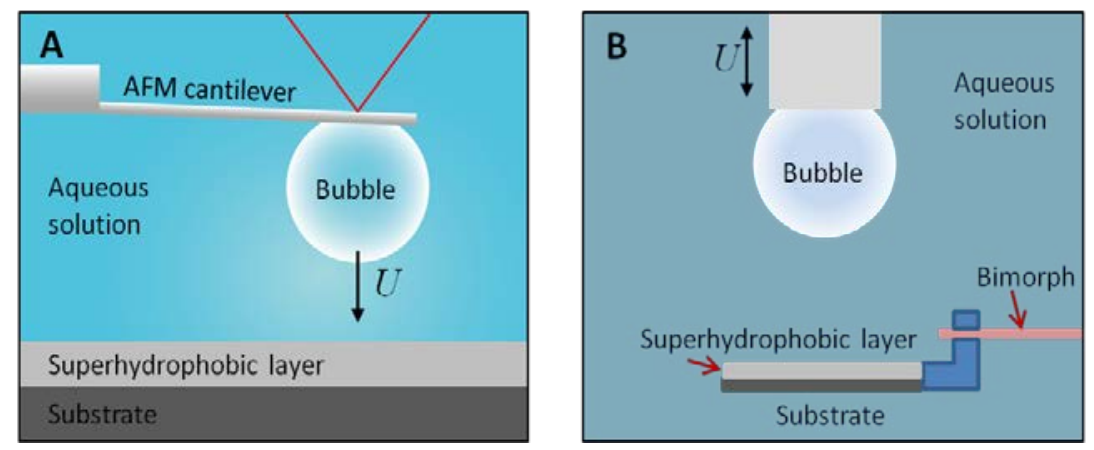

Figure 2. Schematic experimental AFM setup (A) and a modified Integrated Thin Film Drainage Apparatus (B). With these two setups the interaction of superhydrophobic surfaces and microscopic (A) or macroscopic (B) air bubbles were measured. The red line in $(A)$ indicates the laser of the optical lever detection system. 


\section{Theoretical modelling of AFM data}

A theoretical model based on Reynolds lubrication theory and the Young-Laplace equation was used to analyze the AFM experiment results. The deformation of the air bubble in response to the Laplace pressure, hydrodynamic pressure, and the disjoining pressure was described by the Young-Laplace equation: ${ }^{42,43}$

$$
\frac{\gamma}{2 r} \frac{\partial}{\partial r}\left(r \frac{\partial h}{\partial r}\right)=\frac{2 \gamma}{R_{0}}-P-\Pi
$$

Here, $\gamma$ is the interfacial tension, $r$ is the radial coordinate, $h(r, t)$ is the film thickness, and $R_{0}$ is the radius of the air bubble. $P(r, t)$ is the excess hydrodynamic pressure in the liquid film (between air bubble and substrate) relative to the bulk liquid. $\Pi$ is the disjoining pressure arising from surface forces such as van der Waals, electrical double layer interactions. $t$ is time. Reynolds lubrication theory was applied to describe the drainage process of the water film between air bubble and the substrate surface:

$$
\frac{\partial h}{\partial t}=\frac{1}{12 \mu r} \frac{\partial}{\partial r}\left(r h^{3} \frac{\partial P}{\partial r}\right)
$$

Here, $\mu$ is the viscosity of the aqueous solution. Immobile boundary conditions at the air-water and solid-water interfaces were assumed based on recent reports. ${ }^{31,32,33,34,44}$ The overall interaction force between an air bubble and a solid surface $F(t)$ was calculated by integrating $P$ and $\Pi$ based on an approach similar to the Derjaguin approximation: ${ }^{43}$

$$
F(t)=2 \pi \int_{0}^{\infty}[P(r, t)+\Pi(r, t)] r d r
$$

\section{Macroscopic force measurements}

To study the bubble-superhydrophobic surface interaction also at a macroscopic length and faster time scale we carried out experiments with a modified version of Integrated Thin Film Drainage Apparatus (ITFDA) ${ }^{45}$. The ITFDA was used to measure the interaction of an air bubble with radius of $1.2 \mathrm{~mm}$ and a superhydrophobic surface in water. The bubble was generated using a gastight microsyringe at one end of a glass capillary of $0.74 \pm 0.05 \mathrm{~mm}$ inner radius. The substrate of the superhydrophobic surface was clamped the free end of a bimorph cantilever (Fuji Ceramics Corp., $20 \times 3 \times 0.3 \mathrm{~mm}^{3}$, capacitance of $20 \mathrm{nF}$ ). The bimorph is made of two slabs of piezoelectric lead zirconate titanate material sandwiched 
together and used as a bending type force transducer. It was enclosed in a fluorinated ethylene propylene sheath with the other end mounted in a stainless steel measurement chamber which has a glass window for side view observation. When a force is exerted on the substrate it causes a deformation of the bimorph and generates an electrical charge, which was measured by a high impedance charge amplifier. The measured charge can be directly calibrated by adding known weights at the location of the testing surfaces. The sensitivity of the force measurement was $0.1 \mu \mathrm{N}$. The glass capillary with the air bubble attached was moved using a motorized actuator (THORLABS Z825B). The vertical movements of the glass capillary with the bubble were independently measured by a displacement sensor with an accuracy of $5 \mu \mathrm{m}$ and observed with a CCD camera (Basler scA-1400, $17 \mathrm{fps})$. A custom-built LabView program was used for data acquisition and control of the experiments. In this work, the initial distance between the bubble and the surface was set at $400 \mu \mathrm{m}$ with a total displacement of the glass capillary of $600 \mu \mathrm{m}$. Approach and retract velocity were fixed at $1 \mathrm{~mm} / \mathrm{s}$. The volume of the measuring cell was $70 \mathrm{~mL}$ and the submerging depth of the air bubble was $14 \mathrm{~mm}$.

\section{Results and discussion}

\section{Interaction of small air bubbles with soot-templated surfaces}

The most stable and thick Cassie state is obtained with soot-templated surfaces. Therefore, most experiments were carried out with those surfaces. A low and defined ionic strength of $1 \mathrm{mM}$ salt was chosen. When the bubble approached the soot-templated surface with a relatively slow velocity of $1 \mu \mathrm{m} / \mathrm{s}$ it was repelled until a critical force of $\approx 1 \mathrm{nN}$ was reached (Fig. 3 A black line). Then video microscopy showed that the bubble seemed to disappear, similar to the bursting process reported by Wang et al. ${ }^{22}$ In reality, the bubble merged with the air layer trapped in the soot-templated surface. This process was so fast that it could not be resolved with a normal camera or by eye. Thus, the submerged soot-templated surface shows superaerophilic properties in water. 


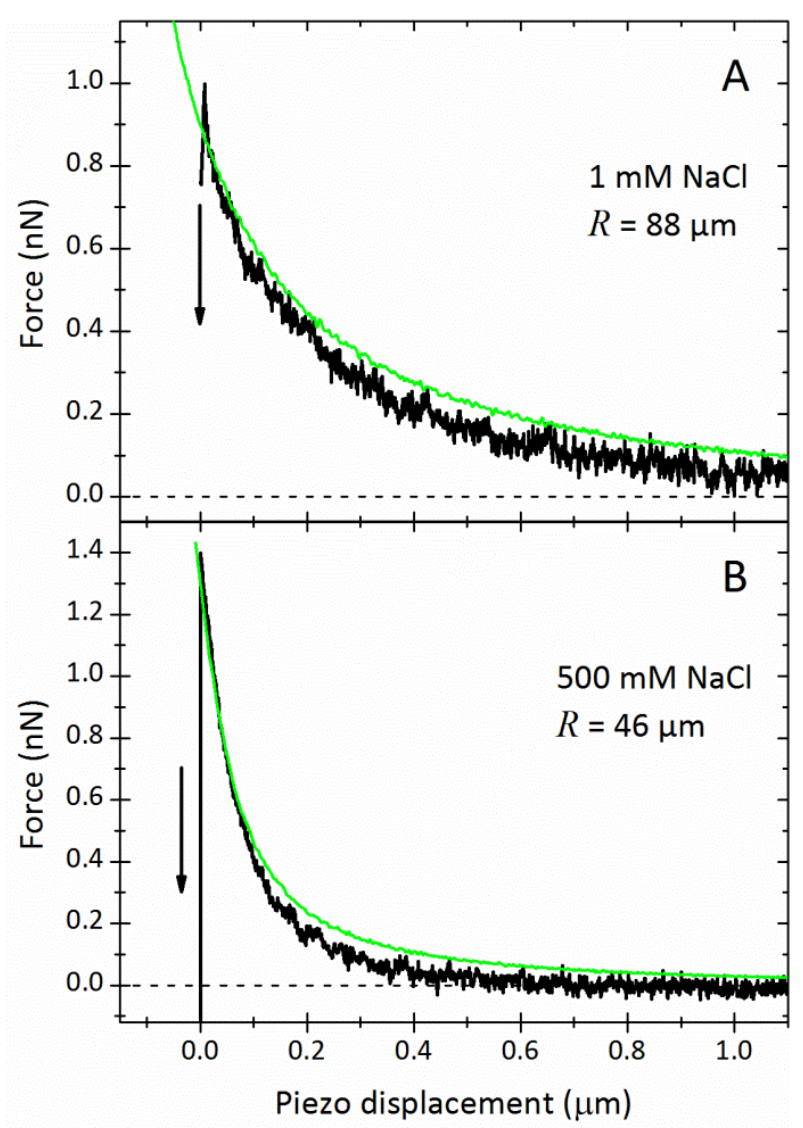

Figure 3. Force-versus-piezo displacement for the interaction of an air bubble attached to an AFM cantilever and a soot-templated superamphiphobic surface (annealing temperature $600^{\circ} \mathrm{C}$ ) in $1 \mathrm{mM} \mathrm{NaCl}(\mathrm{A})$ and in $500 \mathrm{mM} \mathrm{NaCl}(\mathrm{B})$ aqueous electrolyte. Approaching velocity: $1 \mu \mathrm{m} / \mathrm{s}$. Black lines are measured force curves, green curves are theoretical predictions. The radii of the bubbles were $88 \mu \mathrm{m}(\mathrm{A})$ and $46 \mu \mathrm{m}(\mathrm{B})$. In $1 \mathrm{mM} \mathrm{NaCl}$, a surface potential of -35 $\mathrm{mV}$ was taken in the theory, while in $500 \mathrm{mM} \mathrm{NaCl}$ the electrostatic double layer force was neglected. The arrows indicate the "disappearance" of the bubble from the cantilever, leading to a decrease of the force. The zero position of the piezo displacement was set at the jump-in.

The theoretical prediction (Fig. 3A green line) was conducted by assuming that the microbubble on the cantilever interacted with a large air bubble of $10 \mathrm{~mm}$. The large bubble served as a model for the entrapped air layer. In addition to the hydrodynamic force, the theory takes electrostatic double layer and van der Waals forces into account. For the Hamaker constant between the air bubble and air layer in water we used a value of $3.7 \times 10^{-20} \mathrm{~J}$, based on Lifshitz theory. ${ }^{46}$ The van der Waals force including retardation effects has been calculated previously using a rigorous approach; ${ }^{28,47}$ the difference between the 
calculated force curves was very small. The surface potential of both air bubble and air layer was taken to be $-35 \mathrm{mV}$ according to a recent AFM study on air bubble interactions. ${ }^{29}$ The theoretically predicted force curves agree with the experimental curve reasonably well until jump in. This agreement indicates that the electric double layer and hydrodynamic repulsion could effectively delay bubble coalescence. The above calculations assumed an interaction between the microbubble on the cantilever and an air layer of large radius on the substrate.

When increasing the salt concentration to $500 \mathrm{mM}$ aqueous $\mathrm{NaCl}$ solution we still observed a short range repulsive force. This repulsion tended to be stronger than in $1 \mathrm{mM} \mathrm{NaCl}$ (Fig. $3 \mathrm{~B})$, even though in this the radius of the air bubble in $500 \mathrm{mM} \mathrm{NaCl}$ was smaller than that in $1 \mathrm{mM} \mathrm{NaCl}$. Such a stabilizing effect of salt has been observed earlier. Craig et al. found that common electrolytes tend to reduce the rate of coalescence of bubbles. ${ }^{48,49}$ It is not clear yet, how salt hinders bubble coalescence. It seems to be linked to the Hofmeister effect. ${ }^{50}$ It is not due to a change in the hydrodynamic boundary condition. ${ }^{51}$ Increasing the salt concentration reduces the solubility of the dissolved gas in water ${ }^{52}$. It may thus affect the interactions and contribute to the force difference observed in Fig. 3A and 3B.

With the "disappearance" of the bubble the force acting on the AFM cantilever decreased due to the reduced buoyancy of the now missing bubble. The force on the cantilever decreased by $F_{b}=V \rho g$. Here, $V$ is the volume of the bubble, $\rho=998 \mathrm{~kg} / \mathrm{m}^{3}$ is the density of water and $g=9.81 \mathrm{~m} / \mathrm{s}^{2}$ is the acceleration of gravity. With a bubble radius of e.g. $46 \mu \mathrm{m}$ (as in Fig. 3B) the volume of the bubble was $0.41 \mathrm{~nL}$ and $F_{b}=4.0 \mathrm{nN}$. This agrees with the experimental observation but is out of scale of Figure 3B.

\section{Hydrodynamic forces}

A clean fluid interface cannot support shear. To further test if the air layer in the soot-templated surface can support shear, we approached at higher speed to induce stronger hydrodynamic forces. At an approaching velocity of $U=30 \mu \mathrm{m} / \mathrm{s}$ indeed strong distance-dependent hydrodynamic forces were observed (Fig. 4). The force could be increased up to more than $10 \mathrm{nN}$ before the bubble jumped into the layer. In the case shown in Figure 4 the loading force even increased to $32 \mathrm{nN}$ without merging. Only when retracting the cantilever again, the bubble merged with the air layer, denoted at zero piezo displacement. This effect has been observed before for two interacting microbubbles; it is mainly due to the hydrodynamic suction effect. ${ }^{28,33,34}$ After the bubble had merged with 
the air layer in the soot-templated surface, the force was decreased to $-3.6 \mathrm{nN}$ caused by the absence buoyancy.

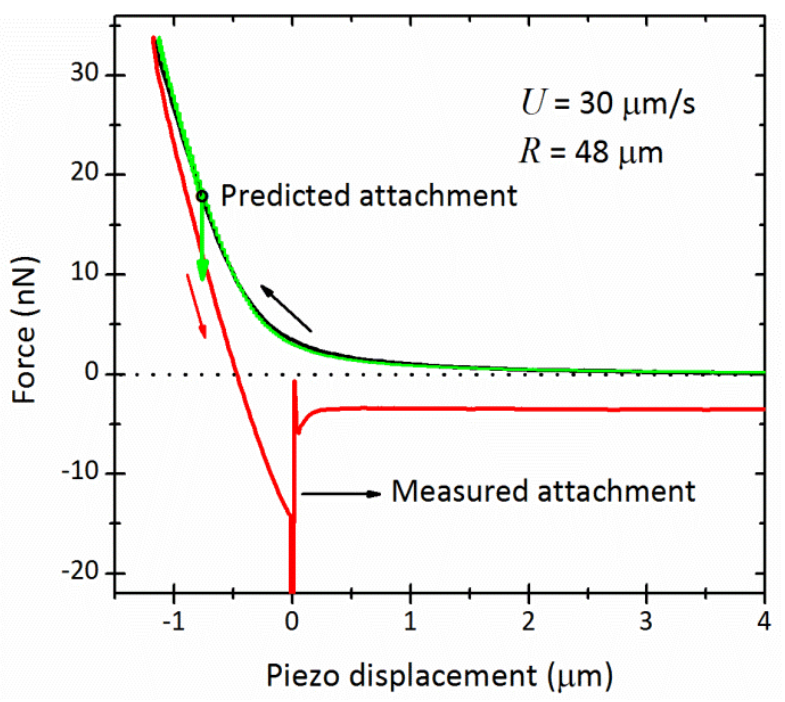

Figure 4. Force versus piezo displacement between an air bubble and soot-templated superamphiphobic layer (annealing temperature $600^{\circ} \mathrm{C}$ ) in $500 \mathrm{mM} \mathrm{NaCl}$ aqueous solution at $30 \mu \mathrm{m} / \mathrm{s}$ approaching velocity. The black part of the curve was recorded during approach, the red part during retraction. The theoretical prediction was conducted by assuming that the microbubble on the cantilever interacted with a layer of air (bottom) of local radius 10 $\mathrm{mm}$, which served as a model for the entrapped air layer. Theoretical calculations (green curve) predict coalescence (dot with green arrow) slightly earlier than the measured data, which might be due to protrusions extending slight beyond the air-water interface.

The fact that strong hydrodynamic forces were observed implies that at the air-water interface the hydrodynamic boundary condition is no-slip rather than no-shear. We attribute this boundary condition to trace amounts of contamination. Measurements of the terminal velocity of rising bubbles in ultraclean water showed that the no shear boundary condition is applicable. ${ }^{53,54}$ Such a high degree of cleanliness is, however, impractical to achieve in our experiments. We suspect that hydrophobic substances adsorb to the superhydrophobic surface during preparation and storage. The substances are slowly and in tiny amounts released into the water of the measuring cell. Since the volume of water is small, the total surface area of the superhydrophobic surface is large, rinsing is impossible during an experiment, and the air-water interface is attractive for hydrophobic substances, trace amounts of contamination are practically difficult to avoid even when working extremely 
clean. That a no-slip boundary condition describes hydrodynamic force measurements in water has been reported before. ${ }^{28}$

\section{Influence of surfactant}

To study the influence of surfactant we added $1 \mathrm{mM}$ sodium dodecyl sulfate (SDS). The surface tension of the $1 \mathrm{mM}$ SDS solution was measured to be $63 \mathrm{mN} / \mathrm{m}$ using a pendent drop goniometer. The presence of surfactant not only ensures an effective no-slip boundary condition, ${ }^{31}$ it also adds charge to the interfaces. Furthermore, it can destabilize the Cassie state due to the reduced surface tension. Soot-templated surfaces remain superhydrophobic even in aqueous surfactant solutions.

Figure 5A shows a force curve recorded with velocity of $U=1 \mu \mathrm{m} / \mathrm{s}$. No jump-in behavior was observed, indicating that the air bubble did not attach or merge with the layer. That the air bubble did not merge but was repelled and separated upon retraction without adhesion was confirmed by the video camera. Again, the air entrapped in the soot-templated surface acts like a large bubble; repulsive forces between two air bubbles in surfactant solution have been observed before. ${ }^{30,31}$ Since SDS is an anionic surfactant it increases the surface charge of the air-water interfaces and leads to an electrostatic double-layer repulsion. 


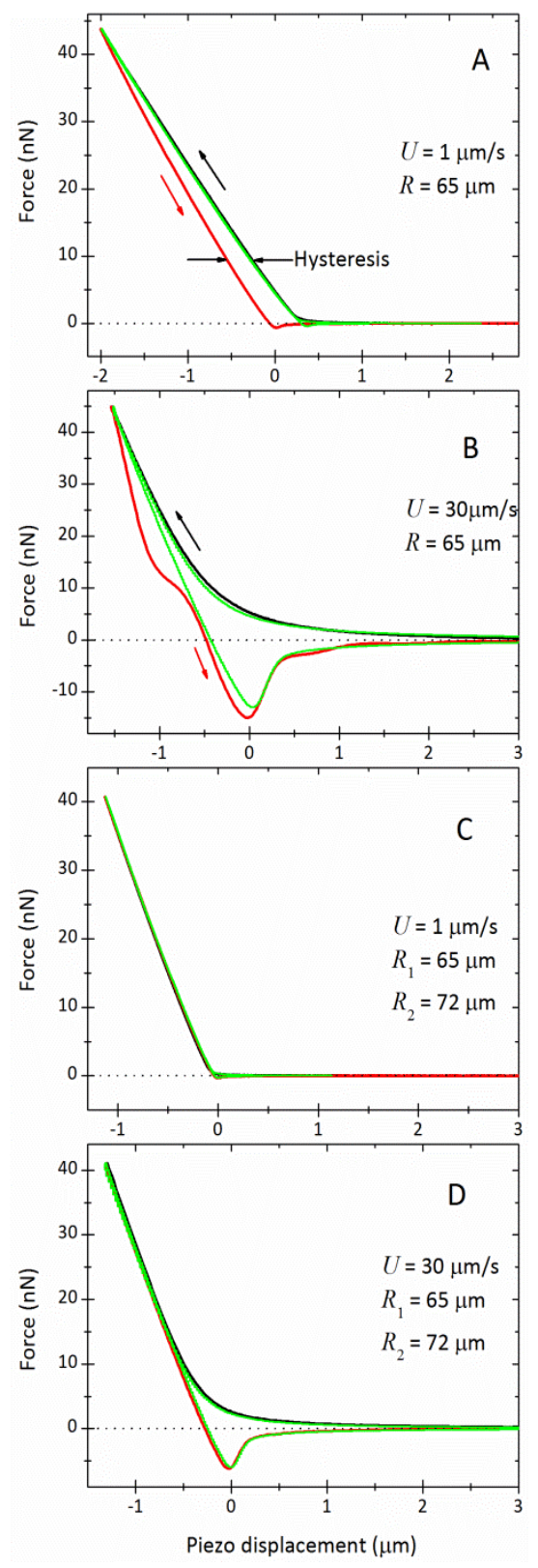

Figure 5. Interaction between an air bubble $(R=65 \mu \mathrm{m})$ and a soot-templated surface (annealed at $600^{\circ} \mathrm{C}$ ) in $1 \mathrm{mM} \mathrm{SDS}$ aqueous solution when approaching with a velocity of 1 $\mu \mathrm{m} / \mathrm{s}(\mathrm{A})$ and $30 \mu \mathrm{m} / \mathrm{s}(\mathrm{B})$. For comparison also the interaction between two bubbles in 1 $\mathrm{mM}$ SDS was measured at $1 \mu \mathrm{m} / \mathrm{s}$ (C) and $30 \mu \mathrm{m} / \mathrm{s}$ approaching velocity (D); one bubble adhered to the bottom of the measuring cell. Approaching curves are plotted in black, retracting curves in red. Theoretical fits are shown in green. The surface potential of the air bubble in $1 \mathrm{mM}$ SDS was fitted to be $-50 \pm 5 \mathrm{mV}$. For the fits in A and $B$ the second bubble was assumed to be large $(R=1 \mathrm{~mm})$. 
Notably, for the interaction with low velocity, considerable hysteresis between approach and retraction curves was observed (Fig. 5A). When replacing the soot-template surface by an air bubble attached to the bottom of the measuring cell, no hysteresis was observed between approach and retraction curves at low velocity $U=1 \mu \mathrm{m} / \mathrm{s}$ (Fig. $5 \mathrm{C}$ ). Therefore, we attribute the hysteresis between approach and retraction to changes in the precise contact line of the air-water interface in the soot-templated surface. The air-water interface is pinned at asperities and the position of the contact line on the asperities can easily change. This effect of a sliding contact line is absent in the interaction of a bubble with the "free" surface of another bubble.

At high velocities (Fig. 5B), the retraction curve showed a wavy shape. From Figure 5B we calculated the frequency of the waves to be around $30 \mathrm{~Hz}$. For comparison, we measured the force between two air bubbles at $30 \mu \mathrm{m} / \mathrm{s}$ approaching velocity. Figure 5D shows that the retraction curve recorded between two air bubbles did not exhibit a wavy shape.

To identify the origin of the waves observed on the soot-templated surface we compare the observed frequency of $\approx 30 \mathrm{~Hz}$ to the first vibration mode of the bubble. The Eigenfrequency of the bubble vibration can be estimated from an approximation of Lauterborn: ${ }^{55,56}$

$$
v=\frac{1}{1.83 R_{\max }} \sqrt{\frac{\Delta P}{\rho}}
$$

$R_{\max }$ is the distance of the largest, local extension of the bubble to its center during the vibration. $\Delta P=2 \gamma / R$ is the pressure across the air/water interface; $R$ is the initial radius of the unperturbed bubble. For an estimation we assume that the amplitude of vibrations is much smaller than the bubble diameter and $R_{\max } \approx R$. With $R_{\max } \approx R$ we obtain

$$
v=\frac{0.77}{R^{3 / 2}} \sqrt{\frac{\gamma}{\rho}}
$$

With a bubble radius of $R=65 \mu \mathrm{m}$ and $\gamma=63 \mathrm{mN} / \mathrm{m}$ we get a frequency $v=11 \mathrm{kHz}$. Thus the $30 \mathrm{~Hz}$ are not related to an Eigenfrequency of the bubble. We believe that the wavy retraction force curve in Fig. 5B is caused by capillary waves of the air layer attached to the soot-templated surface. If we for an estimation insert the frequency of $30 \mathrm{~Hz}$ into Eq. (5) and calculate the effective radius of a bubble corresponding to the entrapped air layer, $R=\left(0.60 \gamma / v^{2} \rho\right)^{1 / 3}$, we obtain a radius of curvature or $R=3.5 \mathrm{~mm}$. Thus the dynamics of capillary vibrations corresponds to that of a macroscopic bubble. 


\section{Interaction between a large air bubble and a soot-templated layer}

To measure the force between a macroscopic air bubble and a soot-templated surface the bubble, formed at the end of a glass capillary, was lowered towards the soot-templated surface (red lines in Fig. 6). The lowering was stopped at a position where the bubble should have contacted the soot-templated surface. Then the position of the capillary was kept constant for $5.3 \mathrm{~s}$. Finally, the capillary was retracted again. The relative position of the capillary and the force was recorded.

When lowering the bubble towards the soot-template surface first a weak repulsion of 33 $\mu \mathrm{N}$ was observed (Fig. 6 top, $t \approx-0.2-0 \mathrm{~s}$ ). Then the bubble jumped into the soot-templated surface and merged with the entrapped air; here we set $t=0$. For the next $\approx 0.3 \mathrm{~s}$ the signal is dominated by an exponentially decaying vibration with a frequency of $\approx 40 \mathrm{~Hz}$. We attribute this vibrations to a capillary vibration of the air in the soot-templated surface or of the bimorph cantilever. After the vibrations had subsided a constant decrease of the force to $-64 \mu \mathrm{N}$ was recorded. This net negative force on the bimorph cantilever was caused by the additional buoyancy. The air added to the soot-templated surface caused a buoyancy equivalent to $F_{b}=V \rho g$. With a bubble radius of $1.2 \mathrm{~mm}$ the volume of the bubble attached to the soot-templated surface was $6.8 \mu \mathrm{L}$ (after a small correction accounting for the air left in the capillary) leading to $F_{b}=67 \mu \mathrm{N}$, which agrees with the observed decrease in force. The force did not change when moving the capillary away from the surface, proving that no capillary bridge between the end of the capillary and the soot-templated layer had formed. The small vibrations at $t=5.5-6.0 \mathrm{~s}$ are due to the movement of the capillary which mechanically couples to the bimorph. 

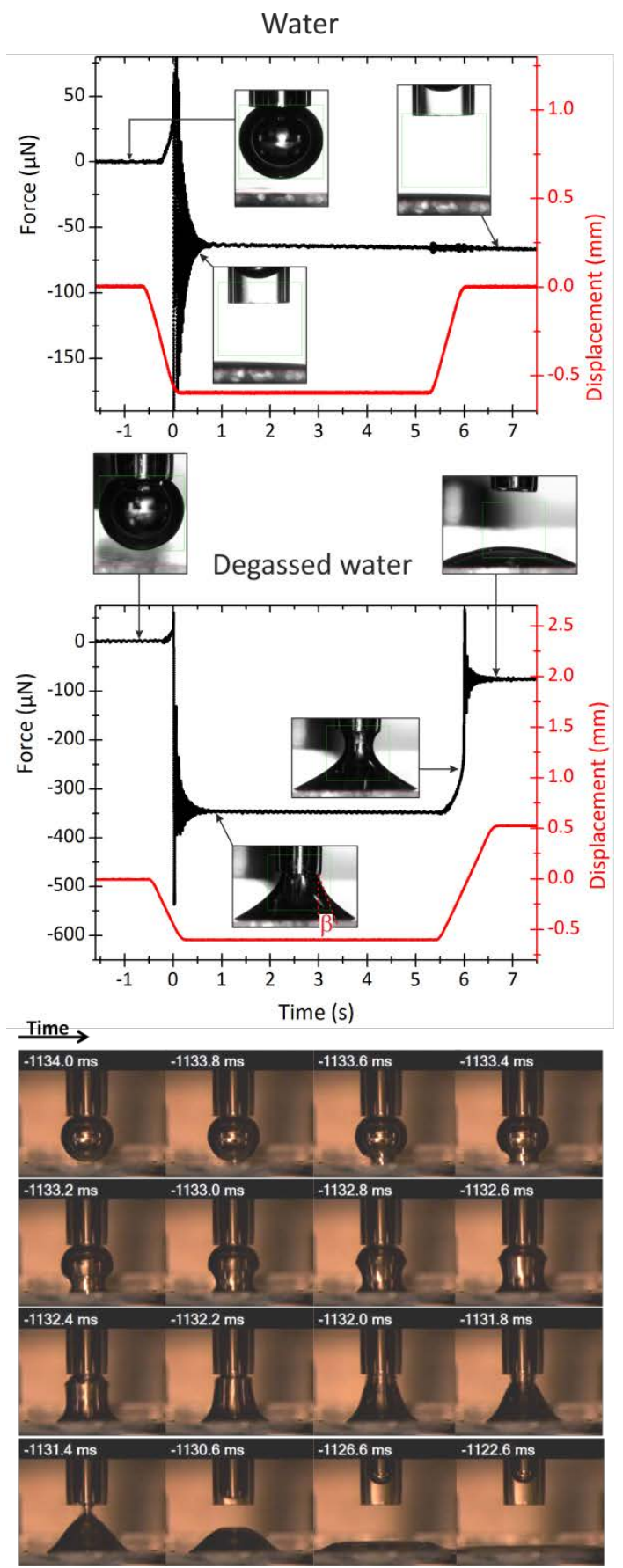

Figure 6. A macroscopic air bubble interacting with a soot-templated surface (annealed at $900^{\circ} \mathrm{C}$ ) in Milli-Q water (A) and in degassed water (B) as measured with the ITFDA. Bubble radius: $1.2 \mathrm{~mm}$, approach/retract velocity: $1 \mathrm{~mm} / \mathrm{s}$. The red line shows the position of the glass capillary with the bubble. Black lines correspond to the force measured by the bimorph. At the bottom a sequence of fast speed camera images show the spreading of an air bubble on soot-templated surface in Milli-Q water recorded at a frame rate of $5000 \mathrm{fps}$. 
The two air-water interfaces approaching each other represent hydrophobic surfaces. It has been speculated that the interaction of two hydrophobic surfaces is influenced by the concentration of dissolved gas. To find out whether the amount of dissolved air influences the interaction, experiments with degassed water were carried out (Fig. 6 bottom). Such experiments are difficult with small bubbles because the air gets dissolved, the bubbles will shrink and disappear during the time required for an experiment. Therefore, we used 1.2 $\mathrm{mm}$ sized bubbles. To reduce the concentration of dissolved air Milli-Q water was boiled close to $100^{\circ} \mathrm{C}$ for $1 \mathrm{~h}$ and cooled down quickly to room temperature in an ice-water bath. Then the degassed water was used right away.

After the initial weak repulsion the bubble jumped into contact with the soot-templated surface (Fig. 6 bottom). Then the bubble formed a capillary bridge rather than merging completely with the air layer. The apparent contact angle of the air-water interface with the soot-templated surface was $29^{\circ}$. The capillary bridge caused an attractive force. The maximal capillary force in vertical direction can be estimated by $F_{c}=2 \pi r \gamma \cos \beta$, where $r$ $=0.74 \mathrm{~mm}$ is the radius of the capillary bridge at its neck and $\beta$ is the angle of the interface with a vertical line. With $\beta=11^{\circ}$ and $\gamma=0.072 \mathrm{~N} / \mathrm{m}$ we estimate a capillary force of $329 \mu \mathrm{N}$. This agrees with the observed decreases in force at $t=0 \mathrm{~s}$ and after the vibrations of 347 $\mu \mathrm{N}$. When the bubble was pulled back from the surface the capillary bridge broke and a flat air bubble with an apparent contact angle of $25^{\circ}$ with respect to air remained on the substrate.

We attribute the formation of a temporary capillary bridge in degassed water to the fact that the entrapped air layer was most likely thinner than in normal water. It was thinner because gas dissolved into the water. As a result protrusions of the soot-templated surface reached further out into the water and acted as pinning sites for the three phase contact line. The apparent advancing contact angle of the bubble was therefore $25^{\circ}$ rather than close to zero. Thus, the interaction of bubbles with superhydrophobic surfaces depends on the amount of entrapped air.

\section{Interaction of small air bubbles with nanofilament surfaces}

When submerging nanofilament surfaces into water typically two types of wetting could be discriminated based on video microscopy (Fig. 7): A "clean" and homogeneous region and a region, which seemed to be under a large bubble but contained water drops. We measured 
the interaction between air bubbles and the "clean" regions, which is most likely a nanofilament region with entrapped air, i.e. in the Cassie state.

When approaching small bubbles towards superhydrophobic nanofilament surfaces they experience a weak repulsive force and a jump-in (Fig. 7). Bubbles did, however, not "disappear" but stayed intact. They only shrank in size. For example the bubble investigated in Figure 7 decreased in radius from $57 \mu \mathrm{m}$ to $54 \mu \mathrm{m}$ after contact had established. Upon retraction a strong adhesive force had to be overcome, indicating the formation of a capillary bridge. The reason for the absence of merging of air may be the reduced thickness of the nanofilament surface and as a result the thinner air layer. In contrast to the soot-templated surface with a thickness of typically $30 \mu \mathrm{m}$, the nanofilament surface was only $4 \pm 2 \mu \mathrm{m}$ thick. Thus, merging and uptake of air from the bubble into the superhydrophobic surface is not a universal feature but depends on its specific architecture and on the contact time.
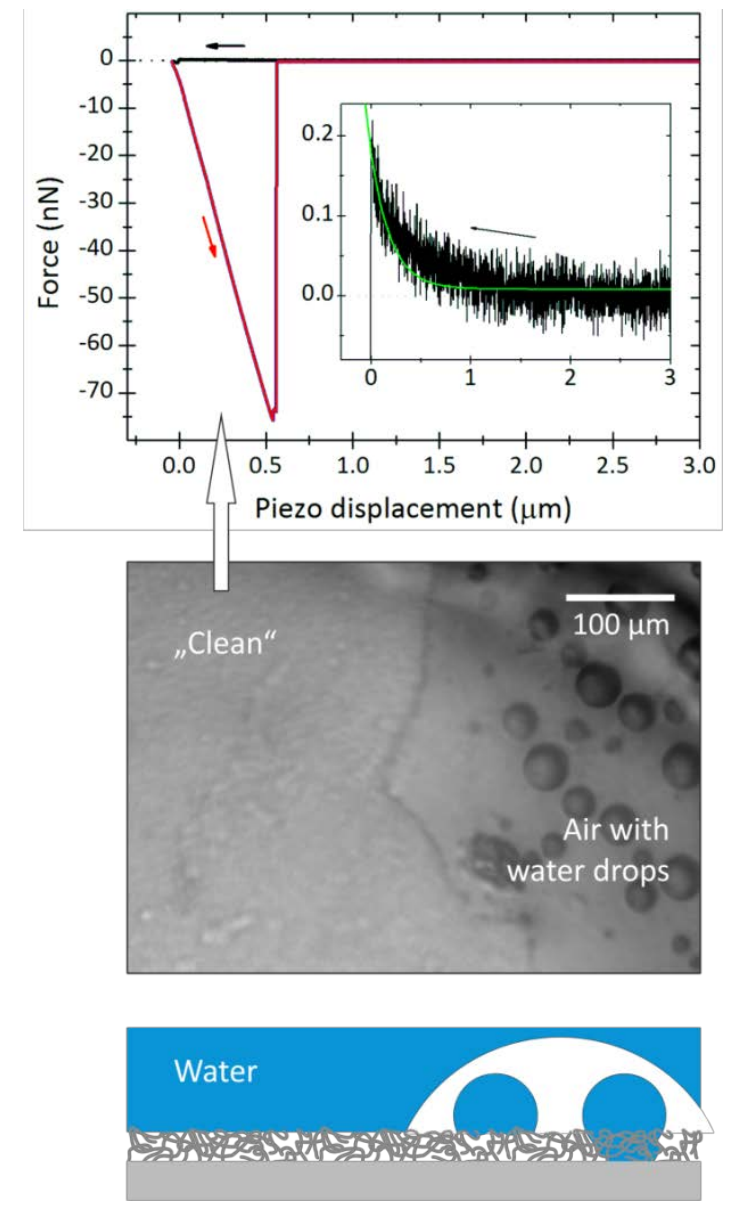

Figure 7. Force-versus-piezo displacement curves for the interaction of a bubble $(R=57$ $\mu \mathrm{m})$ with a nanofilament surface with $1 \mu \mathrm{m} / \mathrm{s}$ approaching velocity and in $1 \mathrm{mM} \mathrm{NaCl}$ recorded in the "clean" region. Experiments were carried out with the AFM bubble setup. The approaching part is plotted in black the retracting part in red. The inset shows the approaching part at higher resolution. The green curve in the inset is the theoretical prediction between an air bubble and an air layer. A light microscope image is shown in the middle. The schematic at the bottom shows water in the Cassie state on a nanofilament region (left) and air with water drops. We cannot discriminate weather the drops are also in the Cassie state (left drop) or in a mixed Cassie-Wenzel state (right drop).

The response observed on nanofilament surfaces was qualitatively similar to the adhesion observed by Wang et al. ${ }^{22}$ In our case the apparent receding contact angle with water was, 
however, larger than $150^{\circ}$ and the surface displayed full superhydrophobicity while the rose petals used by Wang et al. showed a large contact angle hysteresis.

\section{Superhydrophobic micropillar arrays}

When submerging micropillar arrays three types of wetting could be observed (Fig. 8): (I) a large, continuous and thick layer of air with droplets of water inside, (II) a region where the pillars could clearly be seen, and (III) a pillar region with lower contrast. We identify regions II as being in the Wenzel state while regions III are in the Cassie state. This would explain the higher contrast in regions II as compared to region III. We also observed that the area II gradually expanded at the expense of area III. Region I did not change. Forces were measured on regions II and III. Region I looked like the area described as "under a large bubble but contained water drops" on the nanofilament surface. Region III appeared like the "clean" and homogeneous region.
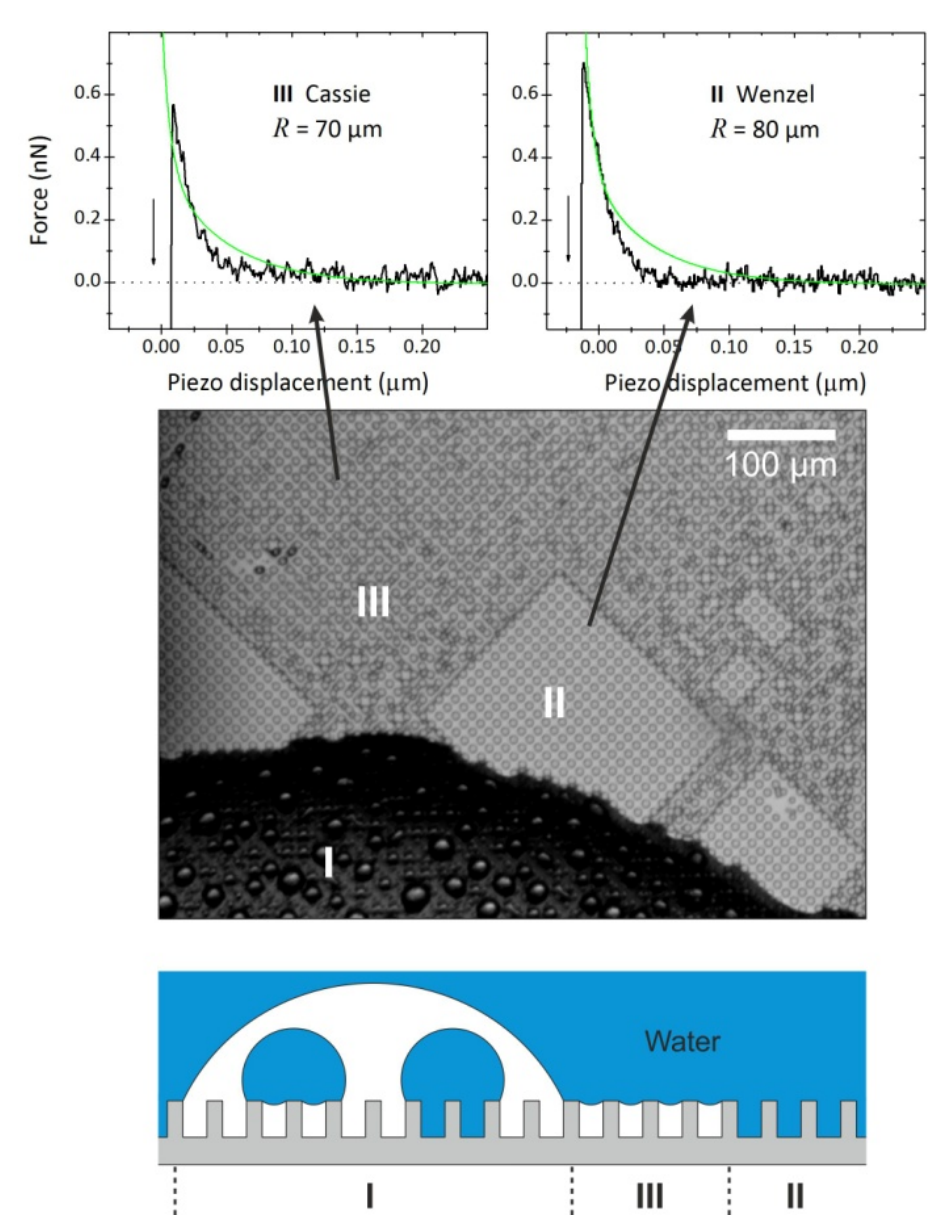

Figure 8. Video microscope image of an array of cylindrical micropillars immersed in $1 \mathrm{mM}$ $\mathrm{NaCl}$ aqueous solution. Three different regions could be distinguished. We interpret these regions as indicated in the bottom schematic. Typical approaching force-versus-piezo displacement curves recorded with the AFM setup in II and III (approaching velocity of $1 \mu \mathrm{m} / \mathrm{s}$ ) are shown at the top. The green curves are theoretical predictions between an air bubble and an air layer (regime III) and between an air bubble and a flat substrate (regime II, surface potential of the solid substrate was

taken as $-40 \mathrm{mV} \cdot{ }^{33,34} \mathrm{R}$ is the radius of the respective bubble in this particular force curve. 
The force curves recorded during approach with microbubbles in regions II and III looked similar. Both showed repulsive force barriers of $\approx 0.6 \mathrm{nN}$. The approach parts resembled the forces observed on soot-templated surfaces. However, the air bubbles showed different behavior during retraction when interacting with the surfaces of region II and region III, as directly observed from the optical microscope. In regions III (Cassie state) the bubble again "disappeared" and merged with the $10 \mu \mathrm{m}$ thick air layer. Thus, the interaction between an air bubble and a micropillar array in the Cassie state can also be described as superaerophilic, just like the submerged soot-templated surface. In regions II (Wenzel state), however, the bubble jumped to the surface but remained on the surface as an intact bubble. It could afterwards be picked up easily with the cantilever again. Thus, in the Wenzel state, the superhydrophobic micropillars do not show superaerophilic properties.

\section{Decorated micropillars}

The results discussed in Figure 8 were obtained with cylindrical pillars with flat tops. When stabilizing the Cassie state by placing microspheres on top of the pillars only two types of regions were observed: I and III. Force curves measured on region III tended to show stronger forces but showed a similar shape as force curves recorded on cylindrical pillars. Typical threshold forces were $\approx 1.3 \mathrm{nN}$ rather than $\approx 0.6 \mathrm{nN}$. The interaction between a bubble and region III was, however, qualitatively different. When a bubble came into contact with the decorated pillars the bubble attached to it (Fig. 9). The cantilever could be moved away while the bubble stayed on the surface. Then the bubble gradually decreased in size and eventually disappeared after 2-3 min. A comparable effect had been described by Change et al. ${ }^{57}$ They observed that on a roughened Teflon surface a large sessile bubble grows at the expense of a neighboring small bubble. This Ostwald type of ripening was attributed to a connection of the bubbles via "network-like pores in the superhydrophobic film which remain nonwetted and provide passage for gas flow between adhered bubbles." 

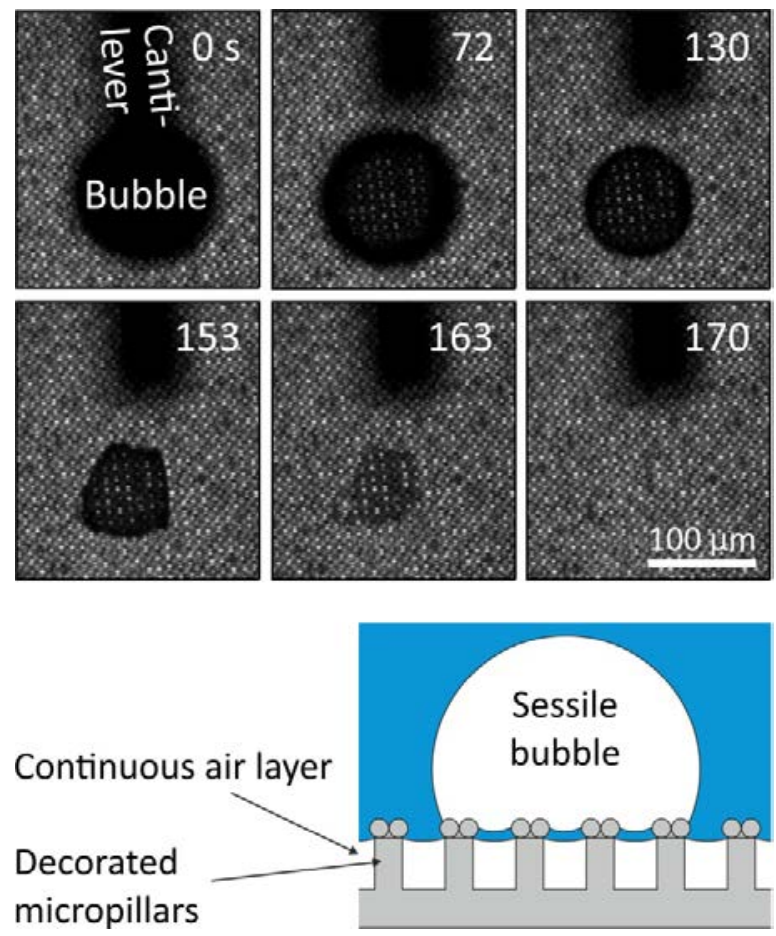

Figure 9. Top: Sequence of video microscope image of a bubble being placed by a cantilever onto decorated micropillars submerged in $1 \mathrm{mM} \mathrm{NaCl}$ aqueous solution. Within $170 \mathrm{~s}$ the bubble dissolves. Bottom: Schematic of a bubble attached to a superhydrophobic surface separated by a liquid lamella from the continuous air layer.

The attachment and gradual shrinking represents another interaction of bubbles with superhydrophobic surfaces in the Cassie state. We speculate that the air from the bubble enters the continuous air layer in the superhydrophobic surface, possibly by diffusion through a liquid lamella (Fig. 9 bottom). The air does not dissolve into solution. Otherwise the air bubble should already dissolve when being attached to the cantilever. The longevity of the bubble on the cantilever proves that the aqueous solution is at almost $100 \%$ saturation with dissolved air. The relative concentration of dissolved air can be estimated with equation 16 of ref. ${ }^{58}$. This equation describes the decreasing radius $R$ of a spherical bubble in an undersaturated liquid:

$$
R^{2}=R_{0}^{2}-\frac{2 D}{\rho_{n}}\left(c_{s}-c_{i}\right) t
$$

Here, $R_{0}$ is the initial bubble radius, $D$ is the diffusion coefficient of gas molecules in the liquid, $\rho_{n}$ is the number density of molecules in the gas phase, $c_{s}$ is the saturation concentration of dissolved molecules in the liquid, and $c_{i}$ is the real concentration of dissolved molecules in the liquid far away from the bubble. Both concentrations are in 
molecules per $\mathrm{m}^{3}$. Eq. (6) is an approximation valid for times, for which a steady state concentration profile has developed around the bubble $(R<<2 \sqrt{\pi D t})$. After one second and with a diffusion coefficient of $D=2.6 \times 10^{-9} \mathrm{~m}^{2} / \mathrm{s}$ for air in water ${ }^{59,60}$ bubbles should therefore be much smaller than $R=180 \mu \mathrm{m}$ for Eq. (6) to hold. This condition was fulfilled in our case.

The life time of a bubble $t_{0}$ can be obtained by setting $R=0$. If we further relate the gas pressure by Henry's law to the saturation concentration, $P=c_{s} k_{H} / N_{A}$, assume an ideal gas, $\rho_{n}=P / k_{B} T$, and replace $c_{s}-c_{i}$ with $c_{s}-c_{i}=c_{s}(1-f)$ we get

$$
t_{0}=\frac{P R_{0}^{2}}{2 D k_{B} T c_{s}(1-f)}=\frac{k_{H} R_{0}^{2}}{2 D R_{g} T(1-f)}
$$

The gas constant $R_{g}=k_{B} N_{A}=8.31 \mathrm{~J} / \mathrm{molK}$ is the product of Boltzmann's constant and the Avogardo number. $f$ is the ratio of the bulk concentration of dissolved air to the concentration at saturation. $P$ is the gas pressure of the gas in equilibrium with water. Eqs. (6) and (7) neglect the additional Laplace pressure in the bubble due to the surface tension of the liquid. This Laplace pressure leads to an overestimation of the lifetime of the order of $20 \%{ }^{58}$

With an effective Henry constant for air in water at room temperature of $k_{H}=1117$ atmL $/ \mathrm{mol}=1.117 \times 10^{5} \mathrm{Nm} / \mathrm{mol}$ and a minimal observed lifetime of a bubble of $50 \mu \mathrm{m}$ radius on the cantilever of $>30$ min we estimate that $f \geq 0.99$. The shrinkage of the sessile air bubble on the decorated micropillars is thus not a dissolution into water. The typical time span still indicates a diffusion process through water as a rate limiting step. Therefore we suggest that between the sessile air bubble and the air layer a liquid lamella exist, as indicated in Fig. 9.

\section{Conclusions}

Bubbles interact in different ways with superhydrophobic surfaces depending on the specific structure of the surface and its wetting state. Phenomenologically interactions can be classified into 
- Superaerophilic, characterized by zero apparent contact angle with respect to air, an immediate jump in after contact followed by complete merging.

- Formation of a capillary bridge with a finite apparent contact angle. In this case the macroscopic contact line seems to be pinned at protrusions reaching out of the entrapped air layer.

- Attachment, in which the bubble attaches to the superhydrophobic surface but largely retains its spherical integrity.

Different wetting states need to be distinguished when submerging the different superhydrophobic surfaces. Wetting states include the Cassie state with different degrees of being filled with air (III in Fig. 8 bottom), the Wenzel state (II), and macroscopic flat air bubbles often including water droplets (I).

The following picture emerges from measurements with microscopic and macroscopic bubbles:

- On soot-templated surfaces the Cassie state is relatively stable. Bubbles interact with such surface in a similar way as with other bubbles: The approaching bubble merges with the entrapped air layer after overcoming hydrodynamic and electrostatic repulsion. The surfaces act perfectly aerophilic with zero apparent contact angle (with respect to air). Soot-templated surface are the most easy ones to be replenished with air by dispersed bubbles.

- Fitting approaching force curves using a theoretical model based on the augmented Young-Laplace equation and Reynolds lubrication theory indicates that the repulsion between the bubble and the air cushion in the superhydrophobic surface is mainly from hydrodynamic and electrostatic (at low salinity conditions) interactions. The hydrodynamic boundary is no-slip. The repulsion increases when adding high salt, despite the fact that the electrostatic force should be reduced. We have no good explanation for this effect yet.

Adding the anionic surfactant SDS leads to a highly stable and repellent interaction due to strong electrostatic and hydrodynamic repulsion. Surfactant prevents merging.

- In undersatured water the thickness of the entrapped air layer decreases. This shrinkage reduces the aerophilicity and makes replenishing the layer with air more difficult.

These experiments only give a rough overview over the rich phenomenology possible in the interaction between bubbles and superhydrophobic surfaces. One of the important next 
steps is to relate these phenomena to the microscopic wetting phenomena on the nanoand microscale.

\section{Acknowledgements}

We thank G. Glaser, G. Schäfer and M. Wagner for technical support. Financial support from ERC grant SuPro (H.J.B.), COST1106 (D.V.), the Marie Curie fellowship 660523-NoBios-ESR (N.E.), the Canadian Centre for Clean Coal/Carbon and Mineral Processing Technologies is gratefully acknowledged. H.Z., C.S., and X.C. acknowledge financial support from the Canada Foundation for Innovation and the Alberta Advanced Education \& Technology Small Equipment Grants Program for the AFM, and the financial support from the Natural Sciences and Engineering Research Council of Canada for the research work.

\section{References}

1. Cassie, A. B. D.; Baxter, S. Large contact angles of plant and animal surfaces. Nature 1945, 155, 21-22.

2. Wenzel, R. N. Resistance of solid surfaces to wetting by water. Ind. Eng. Chem. 1936, 28, 988-994.

3. Watanabe, K.; Udagawa, H. Drag reduction of non-Newtonian fluids in a circular pipe with a highly water-repellent wall. AIChE J. 2001, 47, 256-262.

4. Lee, C.; Choi, C. H.; Kim, C. J. Structured surfaces for a giant liquid slip. Phys. Rev. Lett. 2008, 101, 064501.

5. McHale, G.; Newton, M. I.; Shirtcliffe, N. J. Immersed superhydrophobic surfaces: Gas exchange, slip and drag reduction properties. Soft Matter 2010, 6, 714-719.

6. Rothstein, J. P. Slip on superhydrophobic surfaces. Annu. Rev. Fluid Mech. 2010, 42, 89-109.

7. Gogolides, E.; Ellinas, K.; Tserepi, A. Hierarchical micro and nano structured, hydrophilic, superhydrophobic and superoleophobic surfaces incorporated in microfluidics, microarrays and lab on chip microsystems. Microelectronic Engineering 2015, 132, 135-155.

8. Srinivasan, S.; Kleingartner, J. A.; Gilbert, J. B.; Cohen, R. E.; Milne, A. J. B.; McKinley, G. $H$. Sustainable drag reduction in turbulent Taylor-Couette flows by depositing sprayable superhydrophobic surfaces Phys. Rev. Lett. 2015, 114, 014501. 
9. Paven, M.; Papadopoulos, P.; Schöttler, S.; Deng, X.; Mailänder, V.; Vollmer, D.; Butt, H.-J. Super liquid-repellent gas membranes for carbon dioxide capture and heart-lung machines. Nature Commun. 2013, 4, 2512.

10. Vakarelski, I. U.; Marston, J. O.; Chan, D. Y. C.; Thoroddsen, S. T. Drag reduction by Leidenfrost vapor layers. Phys. Rev. Lett. 2011, 106, 214501.

11. van Gils, D. P. M.; Guzman, D. N.; Sun, C.; Lohse, D. The importance of bubble deformability for strong drag reduction in bubbly turbulent Taylor-Couette flow. J. Fluid Mech. 2013, 722, 317-347.

12. Bobji, M. S.; Kumar, S. V.; Asthana, A.; Govardhan, R. N. Underwater Sustainability of the "Cassie" State of Wetting. Langmuir 2009, 25, 12120-12126.

13. Lei, L.; Li, H.; Shi, J.; Chen, Y. Diffraction patterns of a water-submerged superhydrophobic grating under pressure. Langmuir 2010, 26, 3666-3669.

14. Sakai, M.; Nakajima, A.; Fujishima, A. Removing an air Layer from a superhydrophobic surface in flowing water. Chem. Lett. 2010, 39, 482-484.

15. Hemeda, A. A.; Gad-el-Hak, M.; Tafreshi, H. V. Effects of hierarchical features on longevity of submerged superhydrophobic surfaces with parallel grooves. Phys. Fluids 2014, 26, 082103.

16. Carlborg, C. F.; Stemme, G.; van der Wijngaart, W. Microchannels with substantial friction reduction at large pressure and large flow. IEEE $22^{\text {nd }}$ International Conference on Micro Electro Mechanical Systems 2009, 39-42.

17. Stephani, K. A.; Goldstein, D. B. An examination of trapped bubbles for viscous drag reduction on submerged surfaces. J. Fluids Engineering ASME 2010, 132, 041303.

18. Lee, C.; Kim, C.-J. Underwater restoration and retention of gases on superhydrophobic surfaces for drag reduction. Phys. Rev. Lett. 2011, 106, 014502.

19. Xue, Y.; Chu, S.; Lv, P.; Duan, H. Importance of Hierarchical Structures in Wetting Stability on Submersed Superhydrophobic Surfaces. Langmuir 2012, 28, 9440-9450.

20. Wang, J.; Zheng, Y.; Nie, F.-Q.; Zhai, J.; Jiang, L. Air bubble bursting effect of Lotus leaf. Langmuir 2009, 25, 14129-14134.

21. Krasowska, M.; Ferrari, M.; Liggieri, L.; Malysa, K. Influence of $n$-hexanol and $n$-octanol on wetting properties and air entrapment at superhydrophobic surfaces. Phys. Chem. Chem. Phys. 2011, 13, 9452-9457.

22. Wang, J.; Yang, Q.; Wang, M.; Wang, C.; Jiang, L. Rose petals with a novel and steady air bubble pinning effect in aqueous media. Soft Matter 2012, 8, 2261-2266.

23. Butt, H.-J. A technique for measuring the force between a colloidal particle in water and a bubble. J. Colloid Interface Sci. 1994, 166, 109-117. 
24. Ducker, W. A.; Xu, Z.; Israelachvili, J. N. Measurement of hydrophobic and DLVO forces in bubble-surface interactions in aqueous solutions. Langmuir 1994, 10, 3279-3289.

25. Fielden, M. L.; Hayes, R. A.; Ralston, J. Surface and capillary forces affecting air bubble-particle interactions in aqueous electrolyte. Langmuir 1996, 12, 3721-3727.

26. Preuss, M.; Butt, H.-J. Direct measurement of particle-bubble interactions in aqueous electrolyte: Dependence on surfactant. Langmuir 1998, 14, 3164-3174.

27. Pushkarova, R. A.; Horn, R. G. Bubble-solid interactions in water and electrolyte solutions. Langmuir 2008, 24, 8726-8734.

28. Vakarelski, I. U.; Manica, R.; Tang, X.; O'Shea, S. J.; Stevens, G. W.; Grieser, F.; Dagastine, R. R.; Chan, D. Y. C. Dynamic interactions between microbubbles in water. Proc. Natl. Acad. Sci. USA 2010, 107, 11177-11182.

29. Tabor, R. F.; Chan, D. Y. C.; Grieser, F.; Dagastine, R. R. Anomalous stability of carbon dioxide in pH-controlled bubble coalescence. Angew. Chem. Int. Ed. 2011, 50, 3454-3456.

30. Balasuriya, T. S.; Dagastine, R. R. Interaction Forces between Bubbles in the Presence of Novel Responsive Peptide Surfactants. Langmuir 2012, 28, 17230-17237.

31. Manor, O.; Vakarelski, I. U.; Tang, X. S.; O'Shea, S. J.; Stevens, G. W.; Grieser, F.; Dagastine, R. R.; Chan, D. Y. C. Hydrodynamic boundary conditions and dynamic forces between bubbles and surfaces. Phys. Rev. Lett. 2008, 101, 024501.

32. Tabor, R. F.; Manica, R.; Chan, D. Y. C.; Grieser, F.; Dagastine, R. R. Repulsive van der Waals Forces in Soft Matter: Why Bubbles Do Not Stick to Walls. Phys. Rev. Lett. 2011, 106, 064501.

33. Shi, C.; Chan, D. Y. C.; Liu, Q.; Zeng, H. Probing the hydrophobic interaction between air bubbles and partially hydrophobic surfaces using atomic force microscopy. J. Phys. Chem. C 2014, 118, 25000-25008.

34. Shi, C.; Cui, X.; Xie, L.; Liu, Q.; Chan, D. Y. C.; Israelachvili, J. N.; Zeng, H. Measuring forces and spatiotemporal evolution of thin water films between an air bubble and solid surfaces of different hydrophobicity. ACS Nano 2015, 9, 95-104.

35. Butt, H.-J.; Vollmer, D.; Papadopoulos, P. Super liquid-repellent layers: The smaller the better. Adv. Colloid Interface Sci. 2015, doi:10.1016/j.cis.2014.06.002.

36. Deng, X.; Mammen, L.; Butt, H.-J.; Vollmer, D. Candle soot as a template for a transparent robust superamphiphobic coating. Science 2012, 335, 67-70.

37. Zhang, J. P.; Seeger, S. Superoleophobic coatings with ultralow sliding angles based on silicone nanofilaments. Angew. Chem. Int. Ed. 2011, 50, 6652-6656.

38. Papadopoulos, P.; Mammen, L.; Deng, X.; Vollmer, D.; Butt, H. J. How superhydrophobicity breaks down. Proc. Natl. Acad. Sci. USA 2013, 110, 3254-3258. 
39. Butt, H.-J.; Roismann, I.; Brinkmann, M.; Papadopoulos, P.; Vollmer, D.; Semprebon, C. Characterization of super liquid-repellent surfaces. Curr. Op. Colloid Interfaces Sci. 2014, 19, 343-354.

40. Mammen, L.; Bley, K.; Papadopoulos, P.; Schellenberger, F.; Encinas, N.; Butt, H.-J.; Weiss, C. K.; Vollmer, D. Functional superhydrophobic surfaces made of Janus micropillars. Soft Matter 2015, 11, 506-515.

41. Hutter, J. L.; Bechhoefer, J. Calibration of atomic-force microscope tips. Rev. Sci. Instrum. 1993, 64, 1868-1873.

42. Chan, D. Y. C.; Dagastine, R. R.; White, L. R. Forces between a rigid probe particle and a liquid interface. I. The repulsive case. J. Colloid Interface Sci. 2001, 236, 141-154.

43. Chan, D. Y. C.; Klaseboer, E.; Manica, R. Theory of non-equilibrium force measurements involving deformable drops and bubbles. Adv. Colloid Interface Sci. 2011, 165, 70-90.

44. Schäffel, D.; Yordanov, S.; Schmelzeisen, M.; Yamamoto, T.; Kappl, M.; Koynov, K.; Dünweg, B.; Butt, H.-J. Hydrodynamic boundary condition of water on hydrophilic and hydrophobic surfaces. Phys. Rev. E 2013, 87, 051001.

45. Wang, L.; Sharp, D.; Masliyah, J.; Xu, Z. Measurement of Interactions between Solid Particles, Liquid Droplets, and/or Gas Bubbles in a Liquid using an Integrated Thin Film Drainage Apparatus. Langmuir 2013, 29, 3594-3603.

46. Israelachvili, J. N. Intermolecular and Surface Forces; 3rd ed.; Elsevier: Amsterdam, 2011. p 674.

47. Tabor, R. F.; Wu, C.; Lockie, H.; Manica, R.; Chan, D. Y. C.; Grieser, F.; Dagastine, R. R. Homo- and hetero-interactions between air bubbles and oil droplets measured by atomic force microscopy. Soft Matter 2011, 7, 8977-8983.

48. Craig, V. S. J.; Ninham, B. W.; Pashley, R. M. The effect of electrolytes on bubble coalescence in water. J. Phys. Chem. 1993, 97, 10192-10197.

49. Henry, C. L.; Dalton, C. N.; Scruton, L.; Craig, V. S. J. Ion-specific coalescence of bubbles in mixed electrolyte solutions. J. Phys. Chem. C 2007, 111, 1015-1023.

50. Henry, C. L.; Craig, V. S. J. The Link between Ion Specific Bubble Coalescence and Hofmeister Effects Is the Partitioning of lons within the Interface. Langmuir 2010, 26, 6478-6483.

51. Henry, C. L.; Parkinson, L.; Ralston, J. R.; Craig, V. S. J. A mobile gas-water interface in electrolyte solutions. J. Phys. Chem. C 2008, 112, 15094-15097.

52. Weiss, R. F. The solubility of nitrogen, oxygen and argon in water and seawater. Deep-Sea Research 1970, 17, 721-735. 
53. Kelsall, G. H.; Tang, S.; Smith, A. L.; Yurdakul, S. Measurement of rise and electrophoretic velocity of gas bubbles. J. Chem. Soc., Faraday Trans. 1996, 92, 3879-3885.

54. Parkinson, L.; Sedev, R.; Fornasiero, D.; Ralston, J. The terminal rise velocity of 10-100 $\mu \mathrm{m}$ diameter bubbles in water. J. Colloid Interface Sci. 2008, 322, 168-172.

55. Lauterborn, W. Eigenfrequenzen von Gasblasen in Flüssigkeiten Acustica 1968, 2014.

56. Hund, M. Zur näherungsweisen Berechnung der Eigenfrequenzen von Gasblasen in Flüssigkeiten/Approximate calculation of Eigenfrequency of gas bubbles in liquids. Acustica 1969, 21, 54-56.

57. Chang, F.-M.; Sheng, Y.-J.; Cheng, S.-L.; Tsao, H.-K. Tiny bubble removal by gas flow through porous superhydrophobic surfaces: Ostwald ripening. Appl. Phys. Lett. 2008, $92(26), 264102$.

58. Epstein, P. S.; Plesset, M. S. On the stability of gas bubbles in liquid-gas solutions. J. Chem. Phys. 1950, 18, 1505-1509.

59. Sun, W.-Y.; Kim, C. J. The role of dissoved gas in longevity of Cassie states for immersed superhydrophobic surfaces. $26^{\text {th }}$ IEEE International Conference on MEMS 2013, 397-400.

60. Wilke, C. R.; Lee, C. Y. Estimation of diffusion coefficients for gases and vapors Ind. Eng. Chem. 1955, 47, 1253-1257. 